\title{
Estimation of Age and Growth of Northern Shrimp (Pandalus borealis) in Davis Strait (NAFO Subareas $0+1)$ Using Cluster and Modal Analyses
}

\author{
L. Savard \\ Science Branch, Department of Fisheries and Oceans \\ Maurice Lamontagne Institute, P. O. Box 1000 \\ Mont-Joli, Quebec, Canada G5H $3 Z 4$ \\ D. G. Parsons \\ Science Branch, Department of Fisheries and Oceans \\ Northwest Atlantic Fisheries Centre, P. O. Box 5667 \\ St. John's, Newfoundland, Canada A1C 5X1 \\ and \\ D. M. Carlsson \\ Greenland Fisheries Research Institute, Tagensvej 135, 1 \\ DK-2200 Copenhagen N., Denmark
}

\begin{abstract}
Shrimp (Pandalus borealis) length frequency distributions obtained during research surveys in Davis Strait (NAFO Subareas 0+1) from 1983 to 1987 were analyzed for age and growth. Samples were combined within year on the basis of their similarity using cluster analysis. Modal analyses were performed for males only, separating the distribution mixtures into normal components which were interpreted as ages 1 to 6 , inclusive. Mean carapace lengths at these ages were estimated at 8.4, 12.3, 15.7, 18.5, 20.6 and $22.7 \mathrm{~mm}$, respectively. Females were separated at ages 7 and $8+$ on the basis of biological characteristics with mean lengths of 24.9 and $26.3 \mathrm{~mm}$. A comparison of results from Davis Strait with those reported from other areas in the Northwest Atlantic showed increased longevity and slower growth in the north.
\end{abstract}

Key words: Age composition, Davis Strait, length frequency analyses, Pandalus borealis

\section{Introduction}

The offshore fishery for northern shrimp (Pandalus borealis) in Davis Strait started around 1970 and its importance to both Greenland and Canada has been steadily increasing. Fishery statistics for the offshore area south of $71^{\circ} \mathrm{N}$ indicate total catches of 53000 and 57000 tons in 1990 and 1991, respectively (NAFO, 1992). Yet, with more than 20 years of sampling data, very little has been resolved concerning the age and growth of the animal. Horsted and Smidt (1956) reported that for some near and inshore stocks at West Greenland, age at first maturity for females (the species is protandrous) occurred at 4 or 5 years. Parsons and Tucker (MS 1984) identified the presence of five size groups (ages 0 to 4 ) of males from samples taken in the Canadian offshore fishing grounds. Later, Parsons et al. (1986) found that, in sampling stomachs of cod (Gadus morhua) for ingested shrimp, what was thought previously to be age 0 was more likely age 1. A revised analysis for the Davis Strait stock (Parsons et al., 1989) identified the presence of six modes of males (ages 1 to 6), but it stated that the samples from the Canadian fishery might not be representative of the whole stock area and that, before any definitive statement could be made about growth and maturity, more samples over a longer period and covering a larger area would need to be analyzed.

In this paper, we present the results of a comprehensive study of northern shrimp age and growth in Davis Strait. Samples obtained over a large portion of the offshore grounds from Greenland research surveys (Fig. 1) are assumed to be representative of a single stock resident in the area. Carapace length frequency data are analyzed using a multivariate method to combine similar size distributions which, in turn, are subjected to modal analyses. An interpretation of age and growth is provided and comparison is made with shrimp populations from other areas of the Northwest Atlantic. This 


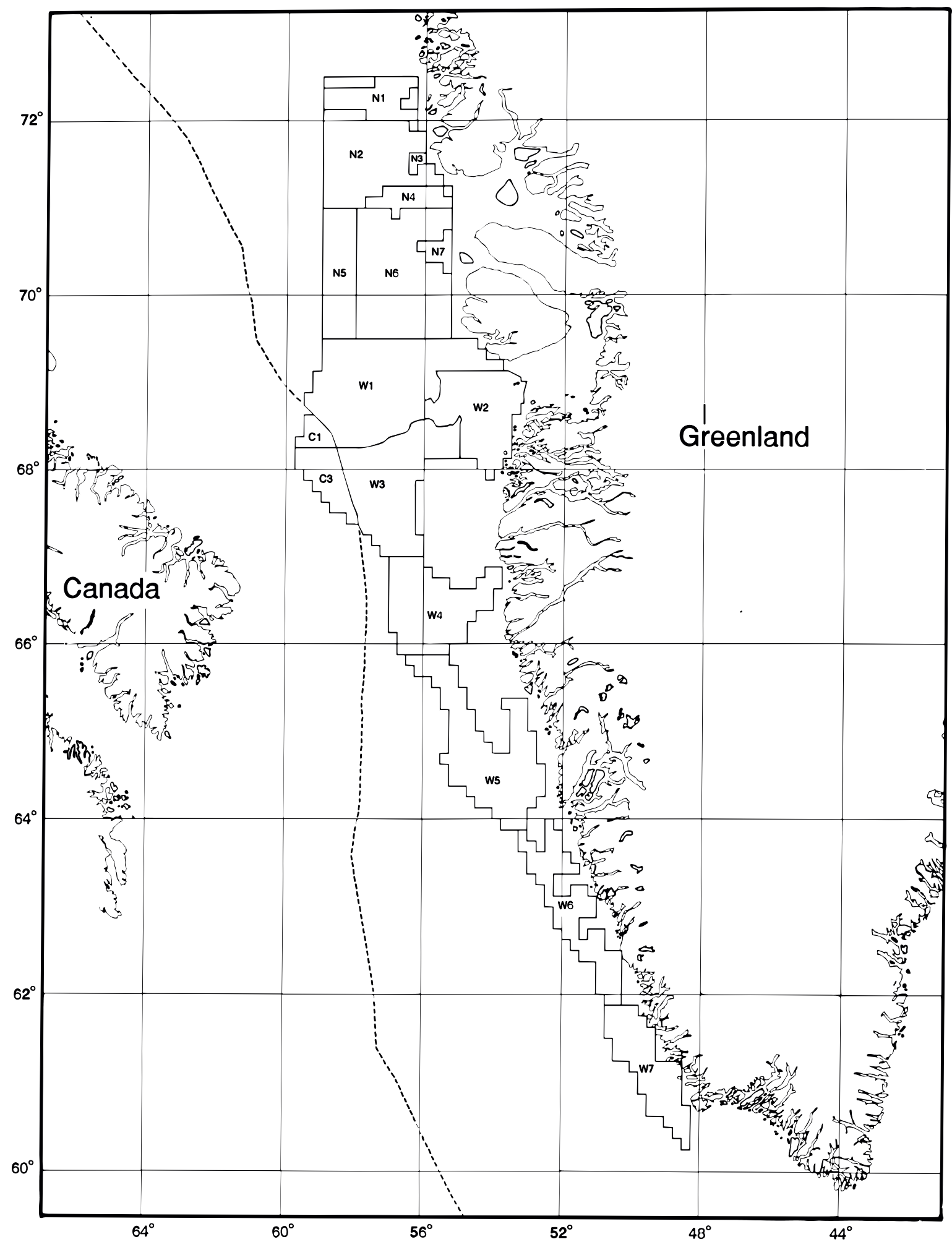

Fig. 1. Survey area in Davis Strait from which samples of shrimp (Pandalus borealis) were taken and analyzed for growth pattern and age composition. Stratum areas W1 to W6, inclusive, and N7 were sampled during the study period. 
study deals exclusively with age and growth but additional information on the demographic structure of the shrimp population in the area can be obtained from the data and is a logical extension of the current work.

\section{Materials and Methods}

Samples of northern shrimp, collected during July-August research surveys in Davis Strait by the Greenland Fisheries Research Institute from 1983 to 1987, were analyzed for age composition. Random samples, from day-time trawl catches of the $\mathrm{R} / \mathrm{V}$ Adolf Jensen, were frozen and later examined for biological information at the laboratory. Oblique carapace lengths were measured to the nearest 0.1 $\mathrm{mm}$ and subsequently combined to $0.5 \mathrm{~mm}$ for analysis. Males and females were separated based on the characteristics of the endopod of the first pleopod (Rasmussen, 1953) and females were further separated into primiparous and multiparous groups based on the prominence of the sternal spines (McCrary, 1971).

A total of 144 samples, with number of shrimp greater than 150, were available for analysis. Within year, a Bray and Curtis (1957) dissimilarity index for length composition was calculated between pairs of samples. A cluster analysis was then performed to group samples with similar size structure. Samples determined to be similar at a level of 0.75 or greater were combined to form homogeneous groups, after being weighted by the survey catch from which the sample was taken. The final combinations were expressed as percent to facilitate plotting and modal analysis of the data.

Modal analyses (MIX - Macdonald and Pitcher, 1979) were performed for males only, on the weighted length distributions of groups of similar samples, to obtain estimates of the mean, proportion and standard deviation of each normal component. Because the data were expressed as percent, the Chi-Square and standard errors of the parameters were not valid, except in a relative sense within each analysis (Macdonald and Green, 1988). The estimates can be considered objective in that each analysis ran freely with no constraints on any of the parameters. Results were tabulated by group and year and mean lengths-at-age were calculated, assuming that the modes represent year-classes. Data from samples with severely overlapped components which could not be resolved by MIX were not included because of the inherent biases created by assigning such means to a particular age.

Mean sizes of primiparous and multiparous females were calculated directly from the combined samples. Using these means for length-at-age assumes that the former constitutes a single cohort and the latter, a composite age group. The proportion of females in several samples was very low and inclusion of the mean sizes from these specimens in an unweighted average might result in a biased estimate of mean length-at-age. Therefore, results of the cluster analysis were used to provide objective criteria for selecting representative groups of samples to calculate the mean lengths of females.

Final estimates of mean length-at-age for shrimp in the Davis Strait were obtained by averaging the results from all reliable samples. In this way, temporal and spatial variability as well as variation in the growth rates of the different cohorts were averaged out. A descriptive comparison with results from other areas of the Northwest Atlantic also is provided.

\section{Results}

The results of the cluster analysis can be best described by observation of the dendrograms (Fig. 2). The original 144 samples were combined into 61 groups based on the similarity indices. Examination of the original length distributions confirmed that combining samples on a similarity level of 0.75 or greater resulted in no loss of information and that the combined samples were, indeed, similar in relation to occurrence and prominence of modes. The combined length distributions (after weighting) for each year (Fig. 3) consistently showed three basic types of size distribution: (1) predominantly small males; (2) larger males with some females; and (3) large males and females.

Modal analyses were conducted on male shrimp from 60 of the 61 groups (Table 1). The determination of sex and maturity from the group omitted (1986 - E) was suspect in that males appeared to have been incorrectly identified as multiparous females and, therefore, was considered unreliable. The results showed the occurrence of six distinct size groups in 3 of the 5 years. All six modes were not evident in any single group of samples but, in those where a broad size range was evident, the largest sizes tended to be severely overlapped and indistinct. In the groups of samples comprised of small males, the first three to four modes were clearly present as were the last two to three in those comprised of large males. The carapace lengths associated with these modes occurred at approximately $8.5,12.5,15.5,18.5,20.5$ and $22.5 \mathrm{~mm}$ and were assumed to represent the mean lengths at ages 1 through 6, respectively (Parsons et al., 1989). In calculating the mean lengths for each year from the components unaffected by unresolved overlap, it was evident that there was a high degree of consistency between years. However, the estimated lengths at ages 4 and 5 in 1986 were larger than in other years as was the length at age 6 in 1987. The 


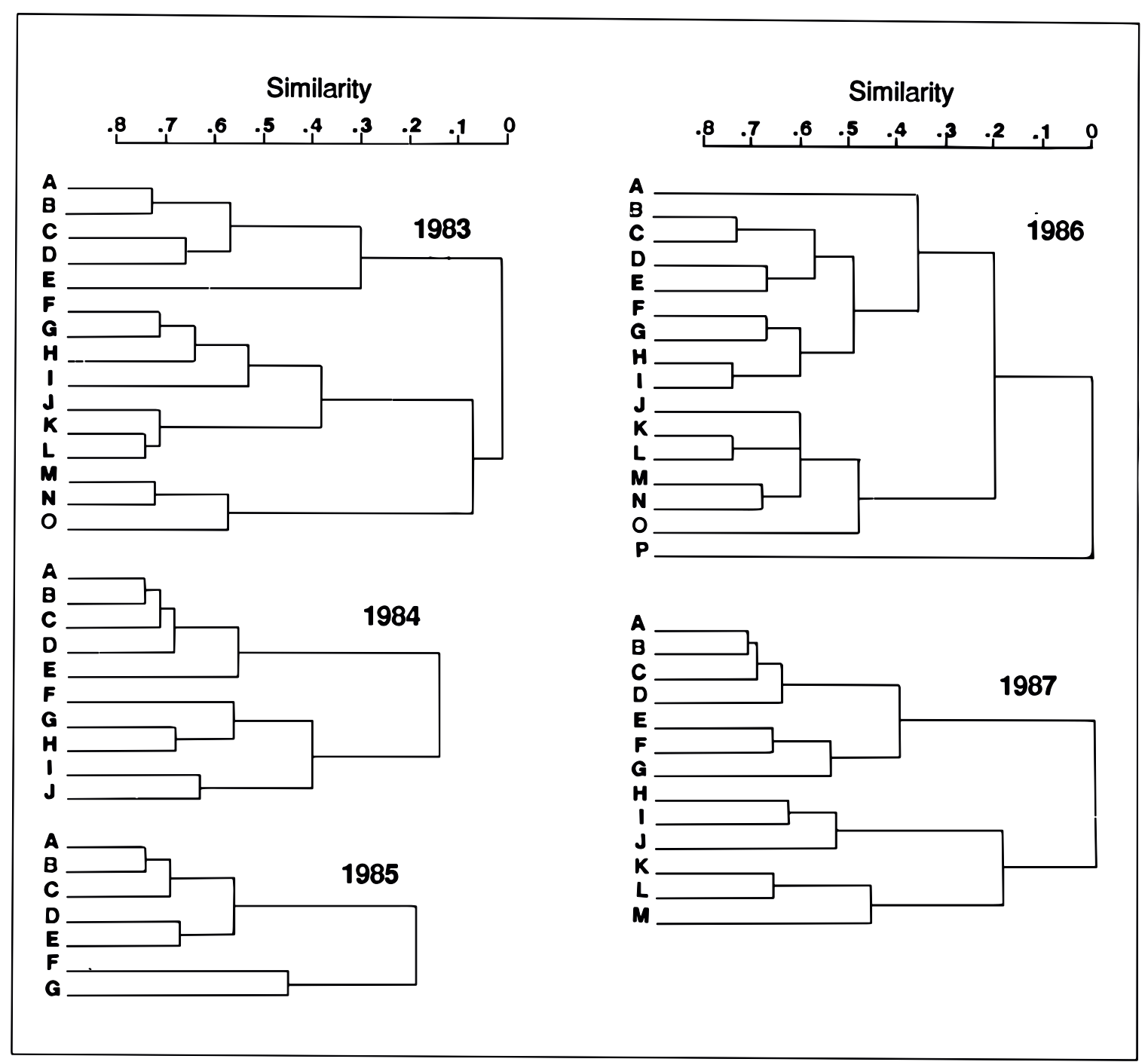

Fig. 2. Dendrograms from the cluster analysis used to combine samples of shrimp (Pandalus borealis) on the basis of similarity of their length frequency distributions.

length at age 6 in 1983, on the other hand, was substantially smaller than for the same age in other years.

Also shown in Table 1 are the mean lengths of primiparous and multiparous females, assumed to represent ages 7 and $8+$, respectively. Considering all samples, the mean size of the former ranged from as low as $18.3 \mathrm{~mm}$ to $26.6 \mathrm{~mm}$ and the latter from 22.7 to $28.0 \mathrm{~mm}$. It is noted not all the values were used in calculating the mean length for each year. The dendrograms from the cluster analysis identified groups of samples in which females were well-represented (Fig. 2 and 3). Based on these observations, the following samples were used to calculate the mean length-at-age for females: 1983
- F to O, $1984-F$ to J, $1985-A$ to E, $1986-A$ to I, and 1987 - A to G. As for the males, the mean lengths of females showed good agreement between years. There was a slight, increasing trend in the size of multiparous females over time and the primiparous females of 1986 and, especially, 1987 were larger than those of the previous three years.

All the data used to calculate the yearly values were included in producing final estimates of lengthat-age for the Davis Strait area (Table 2). The observed annual growth increment from these data showed a gradual decrease from about $4 \mathrm{~mm}$ for the youngest males to $2 \mathrm{~mm}$ for the oldest. The annual increment from ages 4 to 7 (including sex reversal between ages 6 and 7) was fairly stable but 

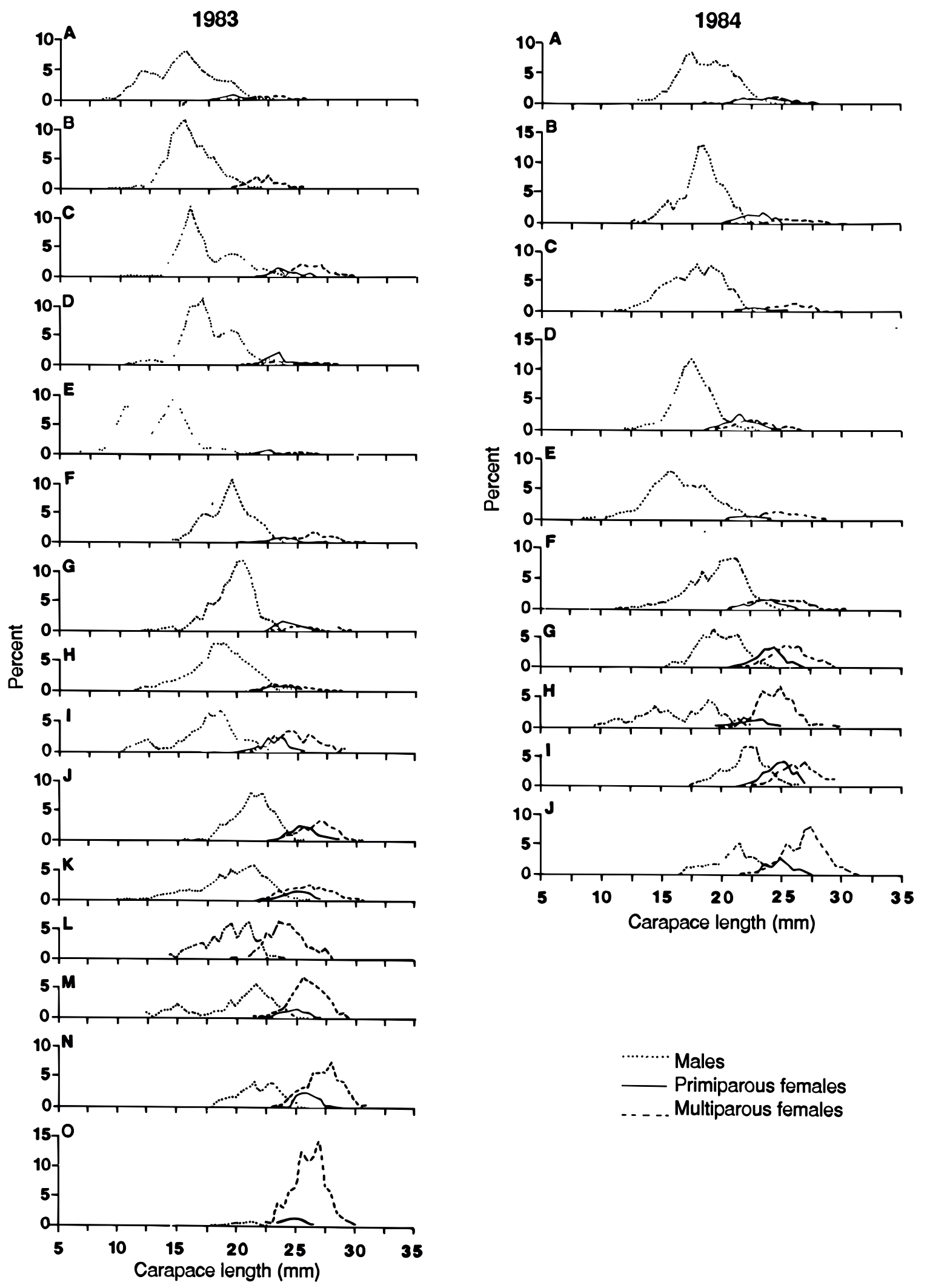

Fig. 3. Weighted length frequency distributions (1983 to 1987) for the groups of shrimp (Pandalus borealis) samples identified from the cluster analysis presented in Fig. 2. Letters assigned to length frequency distributions correspond to those in Fig. 2 and Table 1. 

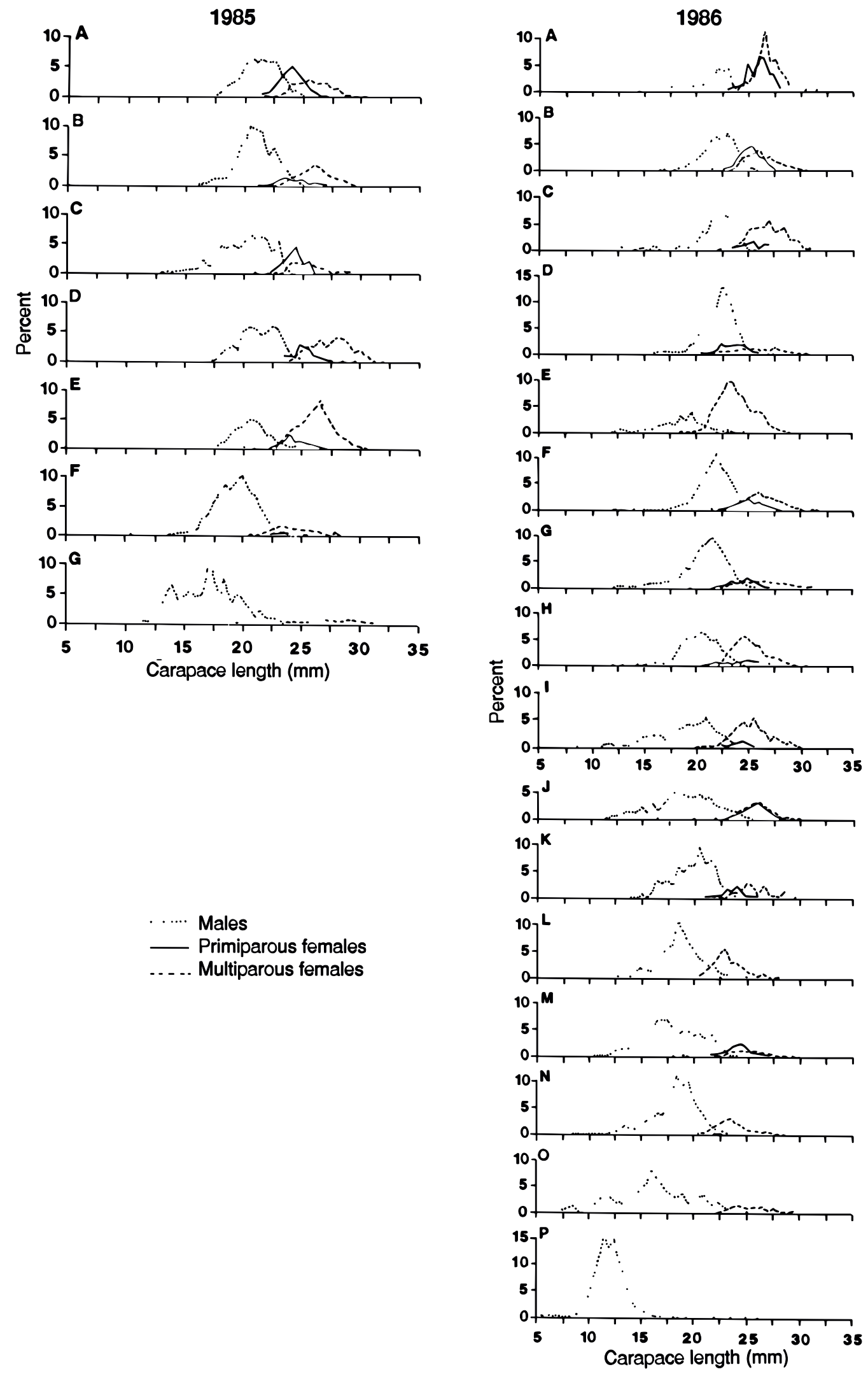

Fig. 3. (Continued). Weighted length frequency distributions (1983 to 1987) for the groups of shrimp (Pandalus borealis) samples identified from the cluster analysis presented in Fig. 2. Letters assigned to length frequency distributions correspond to those in Fig. 2 and Table 1. 


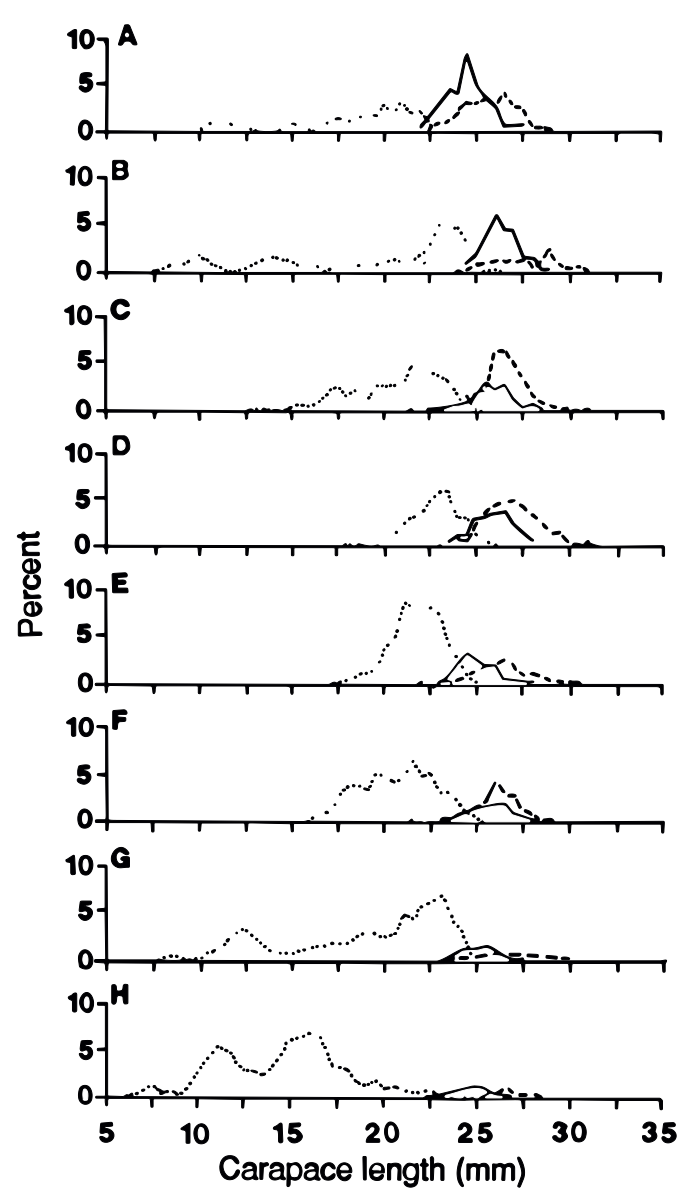

1987

Fig. 3. (Continued). Weighted length frequency distributions (1983 to 1987) for the groups of shrimp (Pandalus borealis) samples identified from the cluster analysis presented in Fig. 2. Letters assigned to length frequency distributions correspond to those in Fig. 2 and Table 1.

then decreased to $1.4 \mathrm{~mm}$ between the female groups (ages 7 and $8+$ ). Because the last group was likely composed of more than one age class, the actual annual increment for female ages was presumed to be less. There was no overlap between the minimum and maximum lengths used to calculate the mean sizes of the younger ages (1 to 4). There was, however, a slight overlap between ages 4 and 5 and the overlap increased for the older ages.

The results from this study for Davis Strait were compared to estimates of mean length-at-age for other areas in the Northwest Atlantic (Table 3, Fig. 4). Estimates from Parsons et al. (1989) for the Newfoundland-Labrador coast were derived from modal analyses (MIX) and are considered directly comparable. Fournier et al. (1991) estimated four or five age-classes in the Gulf of Maine using the MULTIFAN method (Fournier et al., 1990). Since MIX and MULTIFAN are both likelihood-based methods,
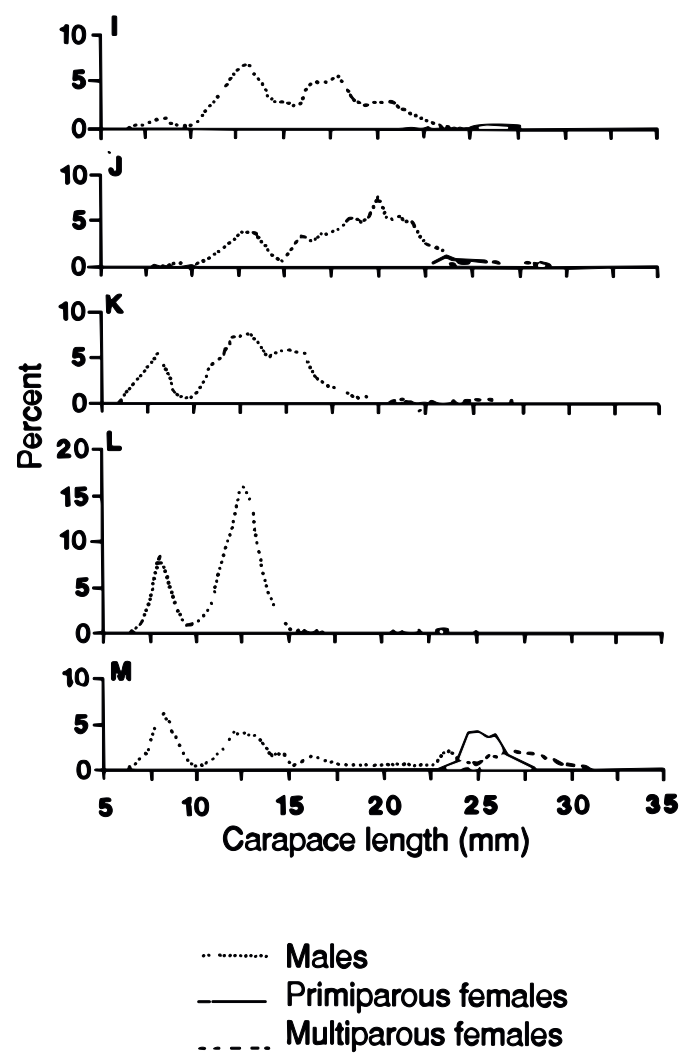

we feel the latter results also are comparable. The findings from the various studies illustrate geographical variation in rates of growth and age at sex reversal for $P$. borealis. From north to south, there was a decrease in longevity and a decrease in the age at sex change. The oldest age decreases were from age $8+$ in Davis Strait and Labrador to age $7+$ off the northeast coast of Newfoundland, and to age 4 or $5+$ in the Gulf of Maine. Sex change occurred between ages 6 and 7 in the two northernmost areas, ages 5 and 6 off northeastern Newfoundland and ages 2 and 3 in the Gulf of Maine. Although the age at sex reversal in the Davis Strait and off the mid-Labrador coast was similar, growth differed to some extent. The growth rate in the former area was greater than in the latter, resulting in larger average sizes for the older animals. Clearly, the population in the Gulf of Maine was faster-growing and shorter-lived than those in more northern areas. 
TABLE 1. Mean carapace lengths $(\mathrm{mm})$ by modal component for Davis Strait shrimp, determined by modal analysis for males and separation of females using sternal spines. Values flanked by "......" indicate more than one mode for which the overlap could not be resolved. Sample groups used for the calculation of mean lengths of females are denoted by "*”. "Group" represents the groups of samples identified by the cluster analysis (Fig. 2), (n) is the number of samples in the group, M1 to M6 refer to modal components of males, and Fp and Fm denote primiparous and multiparous females, respectively.

\begin{tabular}{|c|c|c|c|c|c|c|c|c|c|c|c|}
\hline $\begin{array}{l}\text { Group } \\
\text { (n) }\end{array}$ & M1 & M2 & \multicolumn{2}{|l|}{ M3 } & \multicolumn{2}{|l|}{ M4 } & \multicolumn{2}{|l|}{ M5 } & \multirow[t]{2}{*}{ M6 } & \multirow[t]{2}{*}{$\mathrm{Fp}$} & \multirow[t]{2}{*}{$\mathrm{Fm}$} \\
\hline \multicolumn{9}{|c|}{1983} & & & \\
\hline$A(1)$ & _ & 12.3 & 15.5 & & 18.7 & & _ & & _ & 19.9 & 23.2 \\
\hline B (2) & - & _ & $\ldots$ & 16.2 & $\ldots$ & & - & & - & 18.3 & 22.7 \\
\hline$C(1)$ & - & - & $\ldots$. & 16.2 & $\ldots \ldots$ & & $20 . \overline{2}$ & & - & 24.1 & 25.8 \\
\hline D (4) & - & $12 . \overline{7}$ & $\ldots$ & 16.6 & $\ldots$ & & 19.4 & & - & 23.8 & 24.9 \\
\hline$E(1)$ & 7.4 & 10.9 & 15.2 & & 18.8 & & - & & - & 22.7 & 25.0 \\
\hline F (3) & - & - & - & & 17.7 & & $19 . \overline{8}$ & & $21 . \overline{5}$ & 23.8 * & 26.3 \\
\hline G (3) & - & - & - & & $\ldots \ldots$ & & 19.9 & & $\ldots$ & 24.5 * & 25.7 \\
\hline$H(6)$ & - & - & - & & 17.6 & & 19.1 & & 21.8 & 23.8 * & 24.5 \\
\hline I (1) & - & $12 . \overline{4}$ & - & & $\ldots \ldots$ & 18.3 & $\ldots$ & & 21.6 & 23.4 * & 25.2 \\
\hline$J(2)$ & _ & _ & - & & - & & $\ldots .$. & 21.5 & $\ldots$ & 25.8 * & 26.9 \\
\hline K (3) & - & - & 15.8 & & 18.8 & & $\ldots$ & 21.4 & & $25.1^{*}$ & 26.1 \\
\hline$L(1)$ & - & - & $\ldots$ & 16.7 & $\ldots$ & & 19.3 & & 21.3 & 23.9 * & 24.4 \\
\hline$M(1)$ & - & - & 15.3 & & - & & $\ldots .$. & 21.7 & $\ldots .$. & 24.9 * & 26.2 \\
\hline$N(3)$ & - & - & - & & - & & $\ldots$ & 22.1 & $\ldots$ & 26.2 * & 27.5 \\
\hline O (2) & - & - & - & & - & & $\ldots$. & 21.0 & $\ldots$. & 25.0 * & 26.3 \\
\hline Mean & 7.4 & 12.1 & 15.5 & & 18.3 & & 19.6 & & 21.6 & 24.6 & 25.9 \\
\hline \multicolumn{12}{|c|}{1984} \\
\hline A (3) & _ & _ & - & & 17.9 & & 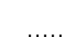 & 21.0 & $\ldots .$. & 23.1 & 23.9 \\
\hline$B(1)$ & _ & _ & 15.8 & & 18.6 & & 20.6 & & - & 23.1 & 25.9 \\
\hline C (2) & - & - & $\ldots$ & 16.3 & $\ldots$ & & $\ldots$ & 19.5 & $\ldots .$. & 23.2 & 25.2 \\
\hline $\mathrm{D}(2)$ & - & - & - & & 17.9 & & $\ldots \ldots$ & 21.1 & $\ldots .$. & 21.9 & 23.0 \\
\hline E (4) & - & $12 . \overline{0}$ & $15 . \overline{9}$ & & 18.8 & & $\ldots \ldots$ & 21.1 & $\ldots \ldots$ & 22.7 & 24.8 \\
\hline$F(8)$ & - & - & 14.5 & & 18.1 & & $\ldots$ & 21.2 & $\ldots$. & 24.0 * & 25.2 \\
\hline G (2) & - & - & - & & 18.9 & & $\ldots$ & 21.1 & $\ldots$ & 24.4 * & 26.0 \\
\hline $\mathrm{H}(1)$ & - & $11 . \overline{3}$ & $14 . \overline{9}$ & & - & & 19.3 & & 21.9 & 23.0 * & 24.9 \\
\hline I (2) & - & - & - & & - & & 19.5 & & 22.7 & 25.2 * & 26.7 \\
\hline$J(2)$ & - & - & - & & $18 . \overline{7}$ & & 21.4 & & 23.4 & 25.1 * & 27.2 \\
\hline Mean & - & 11.7 & 15.3 & & 18.4 & & 20.2 & & 22.7 & 24.3 & 26.0 \\
\hline \multicolumn{12}{|c|}{1985} \\
\hline A (3) & - & - & - & & - & & 20.6 & & 22.6 & 24.3 * & 26.0 \\
\hline B (2) & - & - & - & & $17 . \overline{7}$ & & 20.8 & & 23.2 & 24.3 * & 26.2 \\
\hline C (3) & - & - & $\ldots$ & $\ldots \ldots$ & $\ldots .$. & 20.4 & $\ldots .$. & $\ldots \ldots$ & $\ldots .$. & 24.5 * & 25.5 \\
\hline$D(2)$ & - & - & - & & - & & 20.4 & & 22.8 & 25.5 * & 27.8 \\
\hline$E(1)$ & - & - & - & & - & & 21.0 & & - & 24.6 * & 26.4 \\
\hline$F(2)$ & - & $\begin{array}{l}- \\
-\end{array}$ & $\ldots$ & $\ldots \ldots$ & $\begin{array}{r}- \\
\ldots \ldots\end{array}$ & 20.1 & $\ldots$ & $\ldots$ & $\begin{array}{c}- \\
\ldots \ldots\end{array}$ & 23.5 & 24.6 \\
\hline$G(1)$ & - & $\ldots \ldots 14.1$ & $\ldots .$. & & 17.6 & & $\ldots .$. & 21.8 & $\ldots .$. & 23.8 & 27.4 \\
\hline Mean & _ & _ & _ & & 17.7 & & 20.7 & & 22.8 & 24.6 & 26.4 \\
\hline \multicolumn{12}{|c|}{1986} \\
\hline A (2) & _ & _ & _ & & $\ldots \ldots$ & 19.8 & $\ldots \ldots$ & & 23.2 & 26.3 * & 27.1 \\
\hline B (6) & - & - & - & & 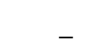 & & 22.0 & & 23.7 & 25.4 * & 26.4 \\
\hline$C(1)$ & - & - & - & & - & & 21.6 & & 23.3 & 25.7 * & 27.1 \\
\hline$D(2)$ & - & - & - & & $\ldots$ & 19.6 & $\ldots .$. & 22.7 & $\ldots .$. & 23.8 * & 26.3 \\
\hline E (2) & \multicolumn{11}{|c|}{ (data from sample considered unreliable) } \\
\hline $\mathrm{F}(4)$ & _ & _ & 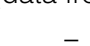 & & 19.0 & & 22.1 & & 23.8 & 25.3 * & 26.4 \\
\hline$G(5)$ & - & - & $16 . \overline{0}$ & & _ & & 20.4 & & 22.0 & 24.7 * & 26.4 \\
\hline $\mathrm{H}(4)$ & - & - & 16.1 & & $19 . \overline{4}$ & & 20.8 & & 21.8 & 24.4 * & 25.3 \\
\hline
\end{tabular}


TABLE 1. (Continued).

\begin{tabular}{|c|c|c|c|c|c|c|c|c|c|c|c|c|}
\hline $\begin{array}{c}\text { Group } \\
\text { (n) }\end{array}$ & M1 & \multicolumn{2}{|l|}{ M2 } & M3 & \multicolumn{3}{|c|}{ M4 } & \multicolumn{2}{|l|}{ M5 } & M6 & \multirow[t]{2}{*}{$\mathrm{Fp}$} & \multirow[t]{2}{*}{$\mathrm{Fm}$} \\
\hline & & & & & 1986 & (Conti & ued) & & & & & \\
\hline I (4) & - & - & & 16.1 & & 18.8 & & 21.2 & & - & 24.3 * & 25.6 \\
\hline J (2) & _ & $\ldots$. & 14.7 & $\ldots$ & & 18.8 & & 21.5 & & 23.8 & 25.9 & 26.1 \\
\hline K (1) & - & _ & & $\ldots$ & 17.3 & 18.8 & & 21.0 & & - & 23.9 & 25.6 \\
\hline L (2) & - & - & & 15.1 & & $\ldots$ & $\ldots \ldots$ & 19.2 & $\ldots$ & $\ldots$ & 22.8 & 23.5 \\
\hline$M(2)$ & - & $\ldots$ & 13.8 & $\ldots$ & 17.3 & $\ldots$ & & 19.8 & & 21.7 & 24.5 & 25.4 \\
\hline$N(4)$ & - & $\ldots$ & 13.7 & 16.3 & & 19.0 & & 21.3 & & - & 22.7 & 23.8 \\
\hline$O(1)$ & 8.2 & 11.9 & & 16.4 & & $\ldots$ & $\ldots$ & 20.5 & $\ldots$ & $\ldots$. & 25.3 & 25.8 \\
\hline$P(1)$ & - & 12.2 & & - & & - & & - & & - & 23.8 & 25.7 \\
\hline Mean & 8.2 & 12.1 & & 16.0 & & 19.0 & & 21.2 & & 22.9 & 25.0 & 26.3 \\
\hline & & & & & & 1987 & & & & & & \\
\hline A (2) & - & 11.6 & & 15.1 & & & & 20.0 & & & $24.7^{*}$ & 26.0 \\
\hline B (2) & $9 . \overline{8}$ & & 14.1 & $\ldots$ & & 18.6 & & 21.0 & & 23.8 & 26.6 * & 28.0 \\
\hline C (1) & - & 13.1 & & - & & 18.4 & & $\ldots$ & 22.6 & $\ldots$ & 26.0 * & 26.8 \\
\hline$D(1)$ & - & - & & - & & 18.7 & & 21.2 & & 23.4 & $26.2^{*}$ & 27.2 \\
\hline E (3) & - & - & & - & & 18.7 & & $\ldots$ & 22.1 & $\ldots$ & 25.2 * & 26.6 \\
\hline$F(2)$ & _ & - & & _ & & 18.8 & & $\ldots .$. & 22.1 & $\ldots .$. & 25.9 * & 26.4 \\
\hline G (2) & - & $12 . \overline{4}$ & & - & & 19.0 & & & 22.9 & $\ldots$ & 25.3 * & 26.7 \\
\hline$H(3)$ & 7.7 & 11.6 & & 16.1 & & - & & 20.0 & & 22.8 & 25.0 & 25.7 \\
\hline I (4) & 8.4 & 13.1 & & $\ldots$ & 17.6 & $\ldots .$. & & 20.9 & & - & 25.6 & 25.8 \\
\hline J (1) & 9.4 & 13.0 & & $\ldots$ & 16.9 & $\ldots$ & $\ldots$ & 20.6 & $\ldots \ldots$ & $\ldots$ & 24.2 & 25.5 \\
\hline K (2) & 8.0 & 12.7 & & 15.6 & & 18.0 & & - & & - & 24.3 & 25.5 \\
\hline L (1) & 8.4 & 12.8 & & - & & - & & - & & - & & 23.6 \\
\hline$M(2)$ & 8.3 & 12.8 & & $16 . \overline{6}$ & & $\ldots$. & 19.1 & $\ldots$ & & $23 . \overline{7}$ & $25 . \overline{5}$ & 27.4 \\
\hline Mean & 8.6 & 12.6 & & 15.9 & & 18.6 & & 20.8 & & 23.4 & 25.7 & 26.8 \\
\hline
\end{tabular}

TABLE 2. Summary of age and growth data for samples of northern shrimp from Davis Strait, 1983-87, combined.

\begin{tabular}{|c|c|c|c|c|c|c|}
\hline \multirow[b]{2}{*}{ Age } & \multirow{2}{*}{$\begin{array}{c}\text { No. of } \\
\text { sample groups }\end{array}$} & \multicolumn{3}{|c|}{ Length (mm) } & \multirow{2}{*}{$\begin{array}{l}\text { Mean length } \\
(\mathrm{mm})\end{array}$} & \multirow{2}{*}{$\begin{array}{l}\text { Increment } \\
(\mathrm{mm})\end{array}$} \\
\hline & & Min. & Max. & Range & & \\
\hline 1 & 9 & 7.4 & 9.8 & 2.4 & 8.4 & 39 \\
\hline 2 & 17 & 10.9 & 13.1 & 2.2 & 12.3 & 3.4 \\
\hline 3 & 18 & 14.5 & 16.6 & 2.1 & 15.7 & 2.8 \\
\hline 4 & 27 & 17.6 & 19.4 & 1.8 & 18.5 & 2.1 \\
\hline 5 & 27 & 19.1 & 22.1 & 3.0 & 20.6 & 2.1 \\
\hline 6 & 22 & 21.3 & 23.8 & 2.5 & 22.7 & 2.2 \\
\hline 7 & 35 & 23.0 & 26.6 & 3.6 & 24.9 & 1.4 \\
\hline 8 & 35 & 24.4 & 28.0 & 3.6 & 26.3 & \\
\hline
\end{tabular}

\section{Discussion and Conclusions}

The use of cluster analysis for objective combination of length frequency data appears to be beneficial from a number of perspectives. The choice of which samples to analyze for age composition is often difficult to make. Most research and commercial sampling programs result in far too 
TABLE 3. Comparison of mean lengths $(\mathrm{mm})$ at age $(\mathrm{yr})$ for northern shrimp from different areas of the Northwest Atlantic ( ${ }^{*}$ first female age).

\begin{tabular}{cccccc}
\hline \hline Age & Davis Strait & $\begin{array}{c}\text { Hopedale Channel } \\
\text { Labrador }\end{array}$ & $\begin{array}{c}\text { St. Anthony Basin } \\
\text { Newfoundland }\end{array}$ & Gulf of Maine 2 \\
\hline 1 & 8.4 & 8.2 & - & 15.7 & 15.7 \\
2 & 12.3 & 13.8 & 13.9 & 20.6 & 20.7 \\
3 & 15.7 & 16.0 & 16.7 & $24.0^{*}$ & $23.8^{*}$ \\
4 & 18.5 & 17.9 & 19.2 & 26.3 & 25.8 \\
5 & 20.6 & 19.5 & 20.5 & & 27.0 \\
6 & 22.7 & 21.4 & $22.9^{*}$ & & \\
7 & $24.9^{*}$ & $23.7^{*}$ & 24.5 & & \\
8 & 26.3 & 25.1 & & & \\
\hline
\end{tabular}

1 Parsons et al., 1989

2 Fournier et al., 1991

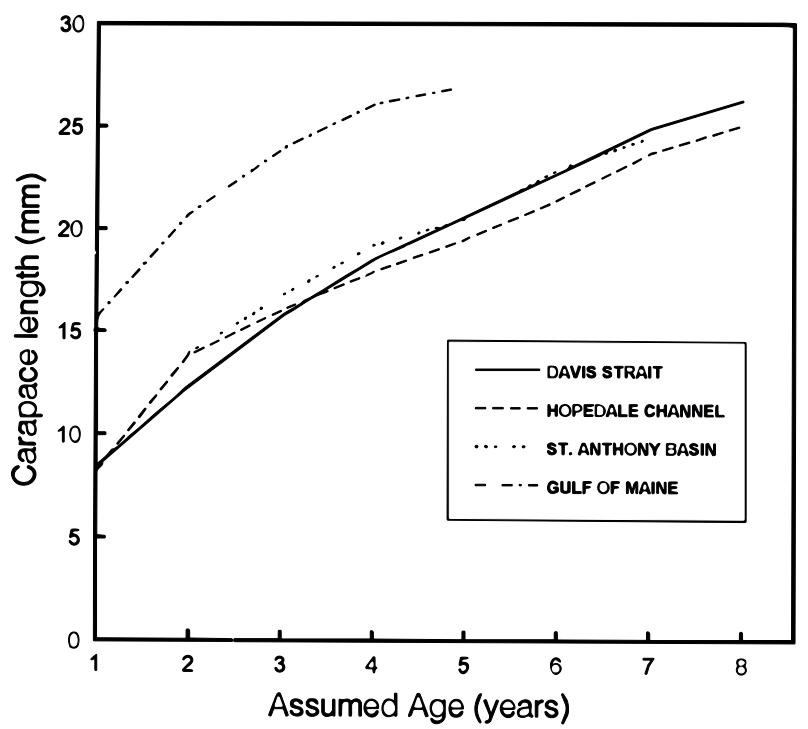

Fig. 4. Comparison of mean carapace lengths-at-age for shrimp (Pandalus borealis) from Davis Strait, Hopedale Channel (mid-Labrador Coast, latitude $56^{\circ} \mathrm{N}$ ), St. Anthony Basin (Northeast Newfoundland, latitude $52^{\circ} \mathrm{N}$ ) and Gulf of Maine (latitude $43^{\circ} \mathrm{N}$ ). The five-age model is shown for the last area (see Table 3).

many length samples for ageing and the investigator is left with the decision of how samples should be combined and which ones are most representative. The methodology used here provides an unbiased and practical solution to the problem. Samples are grouped based on their similarity in size composition and weighting the individual samples by the catch before the combinations are made recognizes the importance of areas where abundance is highest. As evidenced in the present exercise, the number of samples can be reduced considerably through combination without loss of information concerning the number and position of the modes, thus providing results which can be considered representative of the stock or population.

The above methodology also has potential for providing important information on the biology of the species. The application of cluster analysis in the present study demonstrated three basic types of length distributions. Such information can be used on a biogeographical scale to elucidate patterns of distribution and migration within the stock area (see Simard and Savard, 1990). Defining areas where the abundance of either very small or large shrimp are concentrated could provide, for example, insights into the identification of nursery areas and spawning grounds. It is evident, however, that care must be taken in choosing the level of similarity for clustering. In the example given here, information useful for ageing (i.e. the modal structure) would be lost if a similarity level of about 0.6 or less was chosen.

In general, modes occur from year to year at approximately the same sizes both for males and females. However, as mentioned above, there are several inconsistencies on a smaller scale which deserve some discussion. Differences observed in the mean sizes-at-age in some years might be explained by differences in the growth rate of the individual cohorts. The sizes at ages 4 and 5 in 1986, which were noticeably larger than those of the previous years, can be followed forward to large sizes at age 5 and 6 in 1987. The smallest size for primiparous females occurred in 1984 which follows from the smallest age 6 males in 1983. Growth rates of individual year-classes are likely determined by a combination of environmental and density dependent factors. Also, sampling coverage becomes very important if the groups of samples correspond to a well-defined spatial organization. The actual mean size of an age group would be underestimated if the habitat where the largest individuals of that group reside was not sampled due to, say, the vagaries of the sampling design. 
Another important observation from the data affecting the interpretation of the age structure is the inconsistency in the occurrence of the sixth mode of males. In several instances, it is clearly present. In others, it appears to be overlapped with the fifth mode while in yet others, there are no indications of its presence. In this study, we have chosen to treat it as a separate age group but the reasons for its somewhat sporadic occurrence are uncertain at this time.

The proportion of primiparous females in most of the samples is lower than might be expected even though it is recognized that the multiparous females comprise more than one year-class. Sample groups 1983 L, 1984 H, $1986 \mathrm{C}$ and $\mathrm{H}$ are striking examples. The proportions of large males and multiparous females are high in these cases, whereas primiparous females are virtually lacking. Parsons et al. (MS 1987) observed a very low proportion of primiparous females in samples taken in September 1986 and speculated that, although this might suggest a poor year-class, the difficulty in interpreting sternal spines at that time of year was more likely the problem. Females lose their spines on the first moult into breeding dress (McCrary, 1971). In the West Greenland offshore area, spawning usually begins in early-August. Therefore, it is highly likely that pre-spawning moults occur within the research survey period (July-August), the net result being that the sternal spine characteristic, at this time, might not provide a representative separation of primiparous and multiparous groups in all cases.

Despite these uncertainties, results from the analysis appear biologically sound. The annual increments in size decrease as expected over the male age groups and the mean lengths-at-age conform to classical descriptions of growth. Mean lengths are also very similar to those obtained by Parsons et al. (1989) from Canadian research and commercial fishery data. These authors suggested, however, that the data might be sufficiently overlapped to obscure yet another mode at roughly 17 $\mathrm{mm}$ and, if so, a trend of slower growth and increased longevity with increasing latitude would be more firmly established. The more extensive data base analyzed here does not support that possibility.

Comparison of the results from Davis Strait with other areas of the Northwest Atlantic can be considered in relation to the environmental conditions present in each. The Gulf of Maine represents the southern limit of distribution of the species in the western Atlantic, where bottom temperatures range between $5^{\circ}$ and $9^{\circ} \mathrm{C}$ (Mclnnes, 1986). Here, both growth and maturation are accelerated in the relatively warm water, resulting in a life span of at least 5 years. Waters farther north, off the northeastern
Newfoundland and Labrador coasts, are much colder $\left(2^{\circ}\right.$ to $\left.4^{\circ} \mathrm{C}\right)$, and these conditions are reflected in the increasingly smaller sizes-at-age and the delay in sex change. This conforms well to the long established pattern of growth and maturation being delayed in colder water, resulting in increased longevity (e.g. Haynes and Wigley, 1969). However, within the northern areas, there is considerable variation which does not appear to be due to different temperatures. Mean lengths at ages 5, 6 and 7 are similar for the northeastern Newfoundland and Davis Strait areas but sex change occurs a year earlier in the former. Maturity events and Iongevity appear similar in the Labrador Sea and Davis Strait but the overall growth rate is slightly greater in the latter and larger sizes-at-age are attained after age 3 .

Much of the problem in the interpretation of age and growth for northern shrimp, generally, has been due to the difficulty in observing the animals over extended periods, either in situ or under controlled laboratory conditions. Recently, a strong 1985 yearclass was identified in stock assessment exercises (NAFO, 1991) and its growth has been monitored since 1988 when it first appeared at age 3 in samples obtained from the fishery (Parsons and Veitch, MS 1992). Mean lengths-at-age estimated for this year-class by modal analysis of the commercial length frequency data (14.6, 17.5, 20.7 and 21.7 $\mathrm{mm}$ for ages 3 to 6 , respectively) are consistent with the more general estimates provided in this study, supporting our interpretation.

\section{Acknowledgements}

We express thanks to D. E. Stansbury, J. B. Dempson, G. P. Ennis and two anonymous referees for constructive comments on earlier versions of the manuscript.

\section{References}

BRAY, R. J., and J. T. CURTIS. 1957. An ordination of the upland forest communities of southern Wisconsin. Ecol. Monogr., 27: 325-349.

FOURNIER, D. A., J. R. SIBERT, J. MAJKOWSKI, and J. HAMPTON. 1990. MULTIFAN a likelihood-based method for estimating growth parameters and age composition from multiple length frequency data sets illustrated using data for southern bluefin tuna (Thunnus maccoyii). Can. J. Fish. Aquat. Sci., 47: 301-317.

FOURNIER, D. A., J. R. SIBERT, and M. TERCEIRO. 1991. Analysis of length frequency samples with relative abundance data for Gulf of Maine northern shrimp (Pandalus borealis) by the MULTIFAN method. Can. J. Fish. Aquat. Sci., 48: 591-598.

HAYNES, E. B., and R. L. WIGLEY. 1969. Biology of the northern shrimp, Pandalus borealis, in the Gulf of Maine. Trans. Amer. Fish. Soc., 98: 60-76.

HORSTED, Sv. Aa., and E. SMIDT. 1956. The deep sea prawn (Pandalus borealis $\mathrm{Kr}$.) in Greenland waters. 
Medd. Dan. Fisk.-Havunders., N.S., 1(11): 118 p.

MACDONALD, P. D. M., and P. E. J. GREEN. 1988. User's guide to program MIX: an interactive program for fitting mixtures of distribution. Ichthus Data Systems, Hamilton, Ontario, Canada, $60 \mathrm{p}$.

MACDONALD, P. D. M., and T. J. PITCHER. 1979. Agegroups from size-frequency data: a versatile and efficient method of analyzing distribution mixtures. J. Fish. Res. Board Can., 36: 987-1001.

MCCRARY, J. A. 1971. Sternal spines as a characteristic for differentiating between females of some Pandalidae. J. Fish. Res. Board Can., 28: 98-100.

MCINNES, D. 1986. Fishery management plan for northern shrimp. Fish. Manag. Rep., No. 9. Atl. States Mar. Fish. Comm., 76 p. + append.

NAFO. 1991. Scientific Council Reports, 1991. NAFO Sci. Coun. Rep., 1991, 163 p.

1992. Scientific Council Reports, 1992. NAFO Sci. Coun. Rep., 1992, $211 \mathrm{p}$.

PARSONS, D. G., G. R. LILLY, and G. J. CHAPUT. 1986. Age and growth of northern shrimp Pandalus borealis off northeastern Newfoundland and southern Labrador. Trans. Amer. Fish. Soc., 115: 872-881.

PARSONS, D. G., V. L. MERCER, and P. J. VEITCH. 1989.
Comparison of the growth of northern shrimp (Pandalus borealis) from four regions of the Northwest Atlantic. J. Northw. Atl. Fish. Sci., 9: 123-131.

PARSONS, D. G., and G. E. TUCKER. MS 1984. Observations on some biological characteristics of shrimp (Pandalus borealis) from the Davis Strait, 1978-81. NAFO SCR Doc., No. 4, Serial No. N773, 18 p.

PARSONS, D. G., P. J. VEITCH, and V. L. MERCER. MS 1987. Research and commercial fishing for shrimp (Pandalus borealis) in Division OA, 1986. NAFO SCR Doc., No. 1, Serial No. N1269, 18 p.

PARSONS, D. G., and P. J. VEITCH. MS 1992. Analysis of the fishery data for northern shrimp (Pandalus borealis) in Division OA, 1979-1991. NAFO SCR Doc., No. 58, Serial No. N2111, 14 p.

RASMUSSEN, B. 1953. On the geographical variation in growth and sexual development of the deep sea prawn (Pandalus borealis Kr.). Norweg. Fish. and Mar. Invest. Rep., 10(3): 1-160.

SIMARD, Y., and L. SAVARD. 1990. Variability, spatial patterns and scales of similarity in size-frequency distributions of the northern shrimp (Pandalus borealis) and its migrations in the Gulf of St. Lawrence. Can. J. Fish. Aquat. Sci., 47: 794-804. 